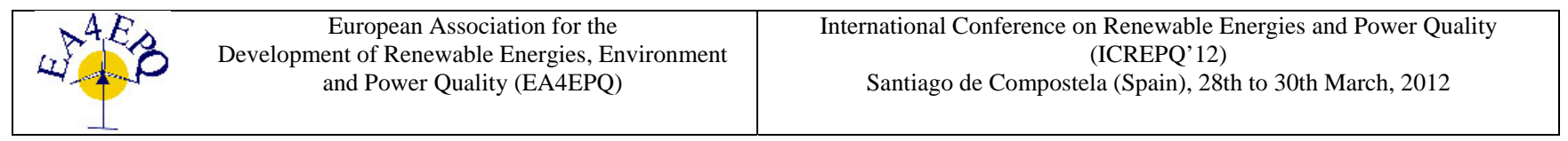

\title{
A practical model to obtain the energy produced by Grid-Connected Photovoltaic Systems (GCPVS) in different parts of the Spanish geography
}

\author{
Rafael M. Lamaison ${ }^{1}$ and Javier Raventós ${ }^{1}$ \\ ${ }^{1}$ Department of Electrical Engineering \\ U.P.C Politecnical University of Catalonia \\ Diagonal 647 Planta 9, ETSEIB \\ 08028 Barcelona, España \\ Tel. 34-93-4010947, Fax. 34-93-4017785
}

Phone/Fax number:+0034 934010947, e-mail: rafael.martin.lamaison@upc.edu

\begin{abstract}
This paper presents a model explaining a way to obtain the energy produced by a Grid-Connected Photovoltaic Systems (GCPVS) in different parts of the Spanish geography. The GCPVS are one of the most important applications of solar photovoltaic energy. The model presented in this work, in addition to losses in system components (panels, inverter and wires), takes into account the effect of temperature losses and accumulated dust and dirt on the photovoltaic modules.

To validate the model results have been presented and compared with the actual data of a photovoltaic plant located in TudelaSpain.
\end{abstract}

\section{Key words}

Grid-Connected Photovoltaic Systems, losses in system, accumulated dirt on the PV modules.

\section{Introduction}

The use of photovoltaic (PV) technology is increasing rapidly in developed and developing countries. The market is currently being driven by concerns about carbon emissions, energy safety and the rising price of fossil fuels.

The basic element that transforms solar energy into electrical energy is the photovoltaic cell. A photovoltaic solar cell can be viewed as a diode designed to maximize the absorption and minimize the reflection of the photons. If the solar cell is illuminated, it creates free charge carriers, which allow the current $I$ to flow through a connected load. In this case, internally in the cell, the current flows from n-type to p-type semiconductor (contrary to the sense of a diode). The number of free charge carriers created is proportional to the incident radiation intensity. This is the photovoltaic effect [1].

The illumination of a solar cell has the effect of adding to the current-voltage characteristic curve of a diode a photocurrent $I_{L}$ internally generated in the solar cell, so that the equation (1) property can be expressed by:
$\boldsymbol{I}=\boldsymbol{I}_{S}\left[\boldsymbol{e}^{\frac{V}{m \cdot V_{T}}}-1\right]-\boldsymbol{I}_{L}$

Where $I_{L}$ is the photo generated current (generated by the photovoltaic effect), $I_{S}$ is the dark saturation current, $V$ is the applied voltage, $m$ is the ideal factor which depends on the material and physical structure of the PN junction which varies between 1 and 2 , and $V_{T}$ is the thermal potential that is defined by the following equation (2):

$V_{T}=\frac{k T}{q}$

Where $q$ is the electron charge $\left(1.6 \times 10^{-19} C\right), K$ is the Boltzmam constant $\left(1.38 \times 10^{-23} \mathrm{~J} / \mathrm{K}\right)$ and $T$ is the absolute temperature.

However, by agreement, the I-V curve of a photovoltaic solar cell is typically represented in the first quadrant by the following equation (3):

$\boldsymbol{I}=\boldsymbol{I}_{L}-\boldsymbol{I}_{S}\left[\boldsymbol{e}^{\frac{V}{m \cdot V_{T}}}-1\right]$

The expression of the power delivered by the cell can be found in the following equation (4):

$$
\boldsymbol{P}=\boldsymbol{V} . \boldsymbol{I}=\boldsymbol{V} . \boldsymbol{I}_{L}-\boldsymbol{V} . \boldsymbol{I}_{S}\left[\boldsymbol{e}^{\frac{V}{m \cdot V_{T}}}-1\right]
$$

For a current value, $I_{m p}$ and a voltage value, $V_{m p}$, the load receives the maximum amount of power $\left(P_{\max }\right)$ delivered by the solar cell. Figure 1 shows the characteristic curves of current - voltage $(I-V)$ and power - voltage $(P-V)$. Since the two curves are represented by the voltage $(V)$ on the horizontal axis, both are displayed in Fig.1. 


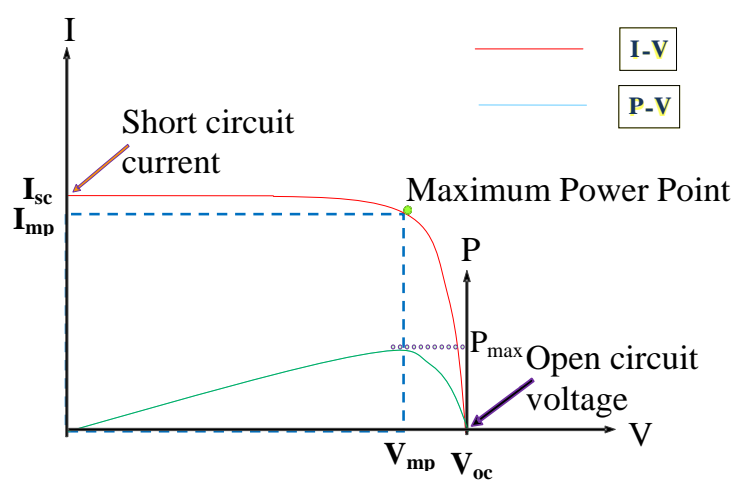

Fig 1. Characteristic curve of power and current versus voltage in a photovoltaic cell.

In Figure 1, $\mathrm{I}_{\mathrm{sc}}$ is the short circuit current and $\mathrm{V}_{\mathrm{oc}}$ is the open circuit voltage.

The two parameters that most affect the electrical characteristics of a solar cell are solar radiation and temperature.

Figures 2 and 3 show the effect of solar radiation and temperature, respectively, in a photovoltaic solar cell. Each of the figures shows the current-voltage (I - V) and power-voltage $(\mathrm{P}-\mathrm{V})$ curve. As you can see on figure 2, the short circuit current of a solar cell increases with the rising level of irradiation, while the open circuit voltage decreases very little [1][2].

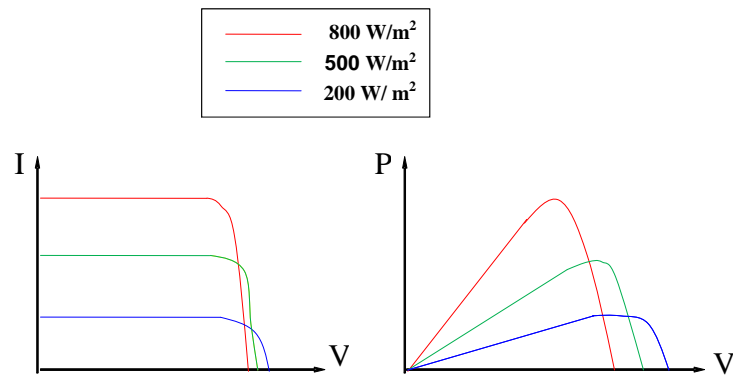

Fig. 2. Effect of solar radiation in a solar cell.

On the other hand, when the temperature increases, the voltage open circuit decreases and the current barely depends on it. However the maximum power point of a photovoltaic solar cell is increased with the increase of solar radiation (Figure 2) and decreases with an increase of temperature (Figure 3).

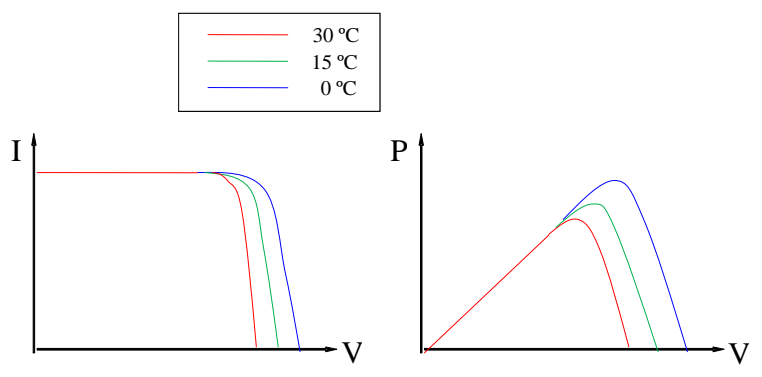

Fig. 3. Effect of the temperature on a solar cell.
For most solar panels, as well as solar cells, when the operating temperature increases, the value of the power output decreases. In practice, due to the dissipation of heat within the cells of the panel, except in very cold climates, the working temperature generally exceeds $25^{\circ} \mathrm{C}$. When this happens, the output never reaches the peak value specified by the manufacturer (remember that the manufacturer gives us the module's peak power, $\mathrm{P}_{\max }$, in standard conditions of measurement, which are 1000 $\mathrm{W} / \mathrm{m}^{2}$ solar radiation and temperature $25^{\circ} \mathrm{C}$ ) [3].

The design of a photovoltaic system must take into account the degradation of the panel to ensure that the power obtained from the system is satisfactory even during the hottest days of summer.

The degradation can be calculated using the values given by the current-voltage curves at high temperature, but this process is tedious and imprecise, given the poor resolution of the curves published by manufacturers. Is therefore much more convenient to use a rate degradation $(\delta)$ given in percentage with respect to the peak power.

Perform calculations for the degradation factor of the panel $(\delta)$, assuming this information is given by the manufacturer. In case this information is unknown, we can assume a degradation rate for the power output that varies between 0.4 and $0.6 \% /{ }^{\circ} \mathrm{C}$.

The operating temperature $\left(T_{o p}\right)$ reaching a $\mathrm{PV}$ panel is given by a linear relationship expression (5):

$T_{o p}=T_{a}+K \cdot R$

Where $T_{o p}$ is the operating temperature, K.R represents the rise of the temperature experienced by the panel, $\mathrm{T}_{\mathrm{a}}$ is the environmental temperature, $\mathrm{R}$ is the solar radiation in $\mathrm{mW} / \mathrm{cm}^{2}$ (varying between 80 and $100 \mathrm{~mW} / \mathrm{cm}^{2}$ ) and $\mathrm{K}$ is a coefficient which varies between 0.2 and $0.4{ }^{\circ} \mathrm{C} . \mathrm{cm}^{2} / \mathrm{mW}$ that depending on the average wind speed, when it is weak or nonexistent, the panel cooling is poor and $K$ takes values close or equal to the maximum (0.4). If the wind speed produces effective cooling of the panel, the value of $K$ will be the minimum $(0.2)$.

To calculate the power output at the operating temperature $\left(\mathrm{P}_{\mathrm{t}}\right)$ reached by a photovoltaic panel, the first step is to calculate the operating temperature $\left(T_{o p}\right)$ and then determining the temperature increase $\left(\Delta_{T}\right)$ over the test (25 $\left.{ }^{\circ} \mathrm{C}\right)$.

The approximate expression for the calculation is:

$$
P_{t}=P_{p}-\left(P_{o p} \cdot \delta \cdot \Delta_{T}\right)
$$

Where $P_{t}$ is the output power at the operating temperature, $P_{p}$ is the peak power of the panel in standard conditions, $\delta$ is the degradation rate (between 0.4 and $0.6 \% /{ }^{\circ} \mathrm{C}$ ) and $\Delta_{T}$ is the temperature increase $\left(T_{o p}-25^{\circ} \mathrm{C}\right)$.

In the proposed model to calculate the photovoltaic electricity production equations 5 and 6 are used to consider the effect of the temperature.

\section{Support structure with solar tracker}

If a surface is moved to follow the sun, the energy yield increases. On days with high insulation and a large direct radiation component, a tracking system provides relatively large radiation gains to be achieved. In summer, a tracking 
system achieves around 50 per cent radiation gains on sunny days, and in winter, 30 per cent or more, compared to a horizontal surface.

There are various types of tracker systems:

- Dual-axis tracking: the surface is always kept perpendicular to the sun. (2x).

- Polar axis: the surface rotates on an axis oriented south and tilted at an angle equal to latitude. (1xp).

- Azimuth axis: the surface rotates about a vertical axis, the angle of the surface is constant and equal to the latitude. (1xa).

- Horizontal axis: the surface rotates on a horizontal axis oriented north-south $(\mathbf{1} \mathrm{xh})$.

The energy gain provided by each of the trackers is not an easy question to respond to because it depends largely on the site where it is situated.

A study to determine the energy gain of solar trackers in respect to a static structure (st) is given in [3]. From that study we can extract the data shown in Table I [4]. This table shows the gain provided by different trackers in terms of electricity actually injected into the network in different parts of the Spanish geography.

Table I: Gain provided by different trackers to the energy actually injected into the network in different parts of the Spanish geography compared with a static installation (st)

\begin{tabular}{|c|c|c|c|c|c|c|}
\hline Place & $G_{a}(0)$ & st & $2 x / s t$ & $1 \times p / s t$ & $1 \times a / s t$ & $1 \times h / s t$ \\
\hline Alicante & 4655 & 4006 & 1.547 & 1.493 & 1.410 & 1.341 \\
\hline Almería & 4706 & 3976 & 1.529 & 1.477 & 1.392 & 1.338 \\
\hline Asturias & 3022 & 2570 & 1.370 & 1.331 & 1.276 & 1.145 \\
\hline Barcelona & 3756 & 3194 & 1.493 & 1.446 & 1.376 & 1.272 \\
\hline Huelva & 4890 & 4052 & 1.575 & 1.522 & 1.431 & 1.392 \\
\hline Jaén & 4416 & 3599 & 1.537 & 1.489 & 1.396 & 1.366 \\
\hline Las Palmas & 4891 & 3874 & 1.493 & 1.444 & 1.295 & 1.363 \\
\hline Lugo & 3488 & 2913 & 1.456 & 1.414 & 1.357 & 1.254 \\
\hline Madrid & 4287 & 3605 & 1.542 & 1.493 & 1.421 & 1.343 \\
\hline Zamora & 4030 & 3341 & 1.522 & 1.477 & 1.418 & 1.333 \\
\hline Nav-Cen & 3499 & 2919 & 1.457 & 1.417 & 1.367 & 1.297 \\
\hline Nav-Nasa & 3794 & 3182 & 1.507 & 1.461 & 1.387 & 1.297 \\
\hline Nav-MdC & 4603 & 4005 & 1.581 & 1.529 & 1.461 & 1.359 \\
\hline
\end{tabular}

\section{Model for predicting energy produced by a photovoltaic solar plant}

Electricity produced by a photovoltaic solar plant connected to the electricity grid will depend, of course, on the power of the PV generator that is installed, the incident radiation on the PV generator and the losses occurred by the system. To obtain the energy production of a photovoltaic solar plant connected to the electricity grid we have to calculate the $k W h / k W p$ ratio [6]. This ratio indicates the energy produced by every $k W p$ of the PV generator that is installed. So, first we need to obtain the monthly incident radiation on the PV generator and then the energy losses, which are grouped in a term called Performance Ratio (PR). For these calculations one must know the location of the plant and establish the optimum angle of inclination for the photovoltaic modules. The model takes into account that the structure of the PV generator can be either static or it can move to follow the sun. If we consider that it is a solar tracker system, the orientation of the structure will vary to optimize the capture of solar radiation.

To apply the model in any location firstly we need the global radiation data on horizontal surface $G_{a}(0)$ as well as the ambient temperature for each month. This data can be obtained from the nearest local meteorological station.

\section{A. Calculating the optimum inclination of a solar panel}

The first step is to calculate the optimum angle of the structure from the following equation (7) given in [5]:

$\beta_{\text {opt }}=3,7+0,69 \phi \quad(\phi$ is the latitude $)$

Radiation obtained by using the optimum inclination of the structure is calculated using the expression (8) given in [5]:

$G a\left(\beta_{o p t}\right)=G a(0) /\left[1-4.46 \times 10^{-4} \beta_{o p t}-1.19_{x} 10^{-4}{\beta_{o p t}}^{2}\right]$

B. Considering the effect of accumulated dirt on the photovoltaic modules

Secondly, the model takes into account the effect of dust and dirt accumulated on the modules. Dust and dirt poses significant losses in the collection of radiation incident on the modules at angles away from the perpendicular. Consideration of this effect was addressed in [5] to develop the following formulation:

$[\operatorname{Geff}(\beta, \alpha)] /\left[G a\left(\beta_{o p t}\right)\right]=g 1\left(\beta-\beta_{\text {opt }}\right) 2+g 2\left(\beta-\beta_{\text {opt }}\right)+g 3$

$g_{i}=g_{i 1} / \alpha T^{2}+g_{i 2} / \alpha F^{2}+g_{i 3} ; i=1,2,3$

Where $\alpha$ is the azimuth (angle of deviation to the south) of the receiving surface and $\beta$ their inclination from the horizontal.

The following table (Table II) contains the values of the coefficients for surfaces with a medium degree of dirt, which means a 3\% loss of transparency on the normal direction to the surface [5].

Table II: Coefficients for surfaces with a medium degree of dirt which are characterized by a 3\% loss of transparency.

\begin{tabular}{|l|c|c|c|}
\cline { 2 - 4 } \multicolumn{1}{c|}{} & \multicolumn{3}{c|}{$\boldsymbol{T}_{\text {dirty }}(\mathbf{0}) / \boldsymbol{T}_{\text {clean }}(\mathbf{0})=\mathbf{0 . 9 7}$} \\
\hline Coefficients & $\mathrm{i}=1$ & $\mathrm{i}=2$ & $\mathrm{i}=3$ \\
\hline $\boldsymbol{g}_{1 j}$ & $8 \times 10^{-9}$ & $3.8 \times 10^{-7}$ & $-1,218 \times 10^{-4}$ \\
\hline $\boldsymbol{g}_{2 j}$ & $-4.27 \times 10^{-7}$ & $8.2 \times 10^{-6}$ & $2.892 \times 10^{-4}$ \\
\hline $\boldsymbol{g}_{3 j}$ & $-2.5 \times 10^{-5}$ & $-1.034 \times 10^{-4}$ & 0.9314 \\
\hline
\end{tabular}

From the statistical average radiation data on horizontal plane and the ambient temperature of the weather station using equation (9) calculate the estimated effective radiation incident on the surface of the generator $\operatorname{Geff}(\beta, \alpha)$. 
Then we will now consider the surface of the tracking system that can be any one of those listed in Table I. Table III below shows the profits given by various sources of information that provide monitoring in terms of solar radiation that actually reaches the solar cells when receiving surfaces have a moderate accumulation of dirt, defined by a normal incidence transmittance, $T a=0.97$ $\left(T_{\text {dirt }}(0) / T_{\text {clean }}(0)\right)[4]$.

Table III: Gains given from different sources using various type of tracking systems, covered with a moderate accumulation of $\operatorname{dirt}(\mathrm{Ta}=0.97)$

\begin{tabular}{|c|c|c|c|c|c|c|c|c|}
\hline & Conslly & IES & CE-h & INM & CE:H & $\ln _{1}, \mid d$ & Metenon & MASA \\
\hline $\mathrm{G}_{\mathrm{d}}(\mathrm{O})$ & 4287 & 4537 & 4605 & 4744 & 4364 & 4406 & 4556 & 4231 \\
\hline $\mathrm{K}_{\mathrm{Ta}}$ & 0.554 & 0.586 & 0.595 & 0.631 & 0.564 & 0.569 & 0.589 & 0,547 \\
\hline $2 x$ & 6666 & 7243 & 7454 & 7795 & 6806 & 6964 & 7278 & 6535 \\
\hline $1 \mathrm{xp}$ & 6447 & 6995 & 7195 & 7518 & 6584 & 6725 & 7036 & 6324 \\
\hline 1xa & 6195 & 6703 & 6881 & 7178 & 6324 & 6453 & 6741 & 6080 \\
\hline $1 \mathrm{xh}$ & 5829 & 6324 & 3474 & 6755 & 5973 & 6062 & 6361 & 5718 \\
\hline St. & 4593 & 4888 & 5011 & 5190 & 4656 & 4755 & 4909 & 4527 \\
\hline $2 \mathrm{x} / \mathrm{st}$ & 1.452 & 1.482 & 1.488 & 1,502 & 1.462 & 1.465 & 1.484 & 1.444 \\
\hline 1xp/st & 1.404 & 1.431 & 1.436 & 1.449 & 1.414 & 1.414 & 1.433 & 1,397 \\
\hline 1xa/st & 1.349 & 1.371 & 1.373 & 1,383 & 1.385 & 1,357 & 1.373 & 1.343 \\
\hline 1xh/st & 1.269 & 1.294 & 1.292 & 1,301 & 1.283 & 1.275 & 1.296 & 1.263 \\
\hline
\end{tabular}

\section{Considering the operating temperature of the solar cell and the wires and inverter losses}

Once we know the actual solar radiation of the generator, we estimate the loss due to the operating temperature of solar cells and due to a variety of phenomena related primarily to the inverter, like conversion efficiency of DC/AC, maximum power point tracking, starting threshold, etc.

Depending on the quality of the inverters, these losses represent between $15 \%$ and $20 \%$, with a typical value around the middle of this range. We must add other losses like the voltage drop in the wiring between the generator and the inverter, dispersion parameters, etc, which can pose an additional $4 \%$. So, the value of PR can vary between 0.7 and 0.75 [7], [8] and [9].

In the model, we will take every loss as unchanged in each month except those due to the operating temperature of the cells:

- Losses associated to the inverters: $16 \%$

- Wiring dispersion parameters, etc: $4 \%$

- Losses due to the operating temperature that depend on the month.

To calculate the operating temperature of the cells use the average ambient temperature of each month and the monthly average radiation at noon, applied to equation (5) given above:

$$
T_{o p}=T_{a}+K \cdot R
$$

To calculate the ratio of output to the operating temperature compared to the peak power $\mathrm{P}_{t} / \mathrm{P}_{\mathrm{p}}$ we can use the formula (6) given above. In this case the operating power is given with respect to the peak power as follows:
To estimate the monthly PR we only consider the losses which were about $20 \%$ (16\% associated to the inverter and $4 \%$ depending on wiring, dispersion parameters, etc).

Finally we estimated the $k W h / k W p$ that a plant of these characteristics could produce. The calculations conclude the possible energy produced in a year ( $k W h$ for each $k W p$ installed) [4][5] and [9].

\section{Validation of the model}

To get an estimation of the raised models reliability, it is interesting to apply them to the actual installation where we know the total energy production in one year. We know the production of the solar PV plant Arguedas (Tudela) was in 2004 and we have the data from the local meteorological station (Forestry Boreas that is the closest to the solar PV plant). The energy actually generated by the PV plant and injected into the grid in the year 2004 was $1745 \mathrm{kWh} / \mathrm{kWp}$. [4].

We will check the reliability of the model from the data of radiation on the horizontal plan $\mathrm{Ga}(0)$ and the average ambient temperatures Temp in ${ }^{\circ} \mathrm{C}$ given at the meteorological station of "Montes del Cierzo" that is the nearest from the Árguedas (Tudela) solar PV plant. These data are shown in the following Table V:

Table V: Solar radiation data and average ambient temperature given by the nearest meteorological station (Montes del CIerzo) from the PV solar plant of Árguedas-Tudela

\begin{tabular}{|c|c|c|c|c|c|c|c|c|c|c|c|c|c|}
\hline & Jan & Feb & Mar & Apr & May & Jun & Jul & Aug & Sep & Oct & Nov & Dec & Anual \\
\hline $\begin{array}{c}\mathbf{G}_{\boldsymbol{a}}(\mathbf{0}) \\
\left(\mathbf{k W h} / \mathbf{m}^{2}\right)\end{array}$ & 54.0 & 72.6 & 123.4 & 156.3 & 202.1 & 228.8 & 221.0 & 217.4 & 146.8 & 97.4 & 69.2 & 46.9 & 1636.1 \\
\hline $\begin{array}{c}\text { Temp. } \\
\text { max.m }\left({ }^{\circ} \mathbf{C}\right)\end{array}$ & 14.2 & 10.6 & 14.0 & 17.3 & 21.5 & 29.9 & 29.7 & 29.9 & 26.7 & 21.6 & 12.7 & 10.4 & \\
\hline
\end{tabular}

From the equation (7) and with the latitude of Árguedas, we can calculate the optimum angle of the structure that is 30 degrees.

Use a statistical average radiation data on horizontal plane, and the equation (8) we can obtain the radiation to the optimum inclination of the structure that is 30 degrees.

Then, using the equation (9) and the Table II we calculate the effective radiation when taking into account the effects of smoothness and dirt.

As $\beta=\beta_{\text {opt }}$ and $\alpha=0$ from equation (9):

$[\operatorname{Geffa}(\beta, \alpha)] / \mathrm{Ga}(\beta \mathrm{opt})]=\mathrm{g} 3=0.9314$

These data are shown in Table VI.

Table VI: Solar radiation data in the horizontal plane, with an inclination of $30^{\circ}$ and effective radiation (considering the effect of dirty) of the PV solar plant Argudas (Tudela).

\begin{tabular}{|l|l|l|l|l|l|l|l|l|l|l|l|l|l|}
\hline $\mathbf{k W h} / \mathbf{m}^{2}$ & Jan & Feb & Mar & Apr & May & Jun & Jul & Aug & Sep & Oct & Nov & Dec & Anual \\
\hline
\end{tabular}

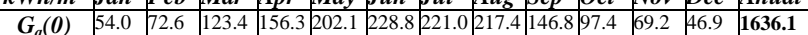

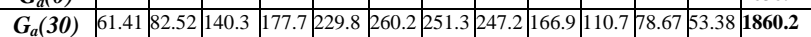

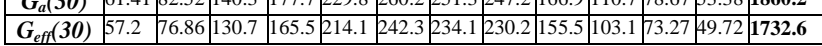

$$
P_{t} / P_{p}=1-(\delta . \Delta T)
$$


Considering the azimuthal tracking as this solar PV plant use and using the Table I the following Table VII show the results for each month:

Table VII: Effective solar radiation data (considering the effect of azimuthal tracking) of the PV solar plant of Arguedas (Tudela)

\begin{tabular}{|c|c|c|c|c|c|c|c|c|c|c|c|c|c|}
\hline & Jan & Feb & Mar & Apr & May & Jun & Jul & Aug & Sep & Oct & Nov & Dec & Anual \\
\hline $\begin{array}{c}\boldsymbol{G}_{\text {eff }} \\
\left(\mathbf{k W h} / \mathbf{m}^{2}\right)\end{array}$ & 77.96 & 104.8 & 178.2 & 225.6 & 291.8 & 330.3 & 319.1 & 313.8 & 211.9 & 140.6 & 99.87 & 67.76 & 2361.5 \\
\hline
\end{tabular}

Table VIII shows the calculations for each month when we consider the effect of temperature.

Table VIII: Effective solar radiation data considering the effect of temperature (PV solar plant of Arguedas - Tudela).

\begin{tabular}{|c|c|c|c|c|c|c|c|c|c|c|c|c|}
\hline & Jan & Feb & Mar & Apr & May & Jun & Jul & Aug & Sep & Oct & Nov & Dec \\
\hline $\boldsymbol{R}$ & 40.0 & 52.2 & 58.4 & 66.0 & 67.6 & 69.8 & 74.0 & 77.8 & 72.3 & 60.3 & 50.1 & 40.9 \\
\hline $\boldsymbol{T}_{\boldsymbol{a}}$ & 14.2 & 10.6 & 14.0 & 17.3 & 21.5 & 29.9 & 29.7 & 29.9 & 26.7 & 21.6 & 12.7 & 10.4 \\
\hline $\boldsymbol{T}_{\boldsymbol{o p}}$ & 27.8 & 32.7 & 37.8 & 42.4 & 47.3 & 54.7 & 59.0 & 59.4 & 53.3 & 43.2 & 34.9 & 28.5 \\
\hline $\boldsymbol{\Delta} \boldsymbol{T}$ & 2.8 & 7.7 & 12.8 & 17.4 & 22.3 & 29.7 & 34.0 & 34.4 & 28.3 & 18.2 & 9.9 & 3.5 \\
\hline $\boldsymbol{P}_{\boldsymbol{t}} / \boldsymbol{P}_{\boldsymbol{p}}$ & $99 \%$ & $97 \%$ & $95 \%$ & $93 \%$ & $91 \%$ & $88 \%$ & $86 \%$ & $86 \%$ & $89 \%$ & $93 \%$ & $96 \%$ & $99 \%$ \\
\hline
\end{tabular}

Finally Table IX gives the total production for each month. The annual production estimated using the proposed model is1767 $\mathrm{kWh} / \mathrm{kWp}$.

Tabla IX: Results energy effectively injected into the network using the proposed model.

\begin{tabular}{|c|c|c|c|c|c|c|c|c|c|c|c|c|c|}
\hline & Jan & Feb & Mar & Apr & May & Jun & Jul & Ago & Sep & Oct & Nov & Dec & Anual \\
\hline $\begin{array}{c}\boldsymbol{G}_{\text {eff }} \\
\left(\boldsymbol{k} \boldsymbol{W h} / \boldsymbol{m}^{2}\right)\end{array}$ & 77.96 & 104.8 & 178.2 & 225.6 & 291.8 & 330.3 & 319.1 & 313.8 & 211.9 & 140.6 & 98.87 & 67.76 & 2361.5 \\
\hline $\boldsymbol{P R}$ & 0.799 & 0.8 & 0.784 & 0.767 & 0.752 & 0.723 & 0.720 & 0.716 & 0.731 & 0.758 & 0.795 & 0.811 & $74.8 \%$ \\
\hline $\begin{array}{c}\text { Prod. } \\
(\boldsymbol{k} \boldsymbol{W h} \boldsymbol{k} \boldsymbol{W} \boldsymbol{p})\end{array}$ & 62.3 & 83.8 & 139.6 & 172.9 & 219.3 & 238.8 & 229.7 & 224.6 & 154.9 & 106.5 & 79.4 & 54.9 & $\mathbf{1 7 6 7 . 0}$ \\
\hline
\end{tabular}

Therefore, we can see that the proposed model works really well take into account that the deviation between the estimated and actual production is only about $1.25 \%$.

\section{Conclusion}

This paper presents a method developed for carrying out the energy production estimation of a photovoltaic (PV) plant in Spain connected to the main supply. The PV solar plant can be with fixed structures or solar tracking devices.

The calculation of the production takes into account the energy losses in the inverter and wire, the temperature losses and the accumulated dirt found in the PV modules.

The model is applied to estimate an actual PV plant located in Arguedas (Tudela). It was observed that the proposed model works really well, allowing us to estimate the energy production and thus provide an economic study of the installation. To confirm that the model works correctly, we have compared the results with an existing plant (Arguedas - Tudela), where the deviation between estimated and actual production model was only $1.25 \%$.
The PV modules were considered as having a medium or moderate amount of dirt accumulate during one year. In this time they were also "cleaned" by the rain thus they did not became encrusted with dirt.

In this manner, an instant calculation was not performed but an annual average was made taking into account the environmental conditions that it would be subjected to during one year. This is why the calculation of the accumulated dirt was considered with a medium degree, which is characterized by a $3 \%$ loss of transparency.

\section{Acknowledgement}

The authors wish to thank the Electronic Engineering Department of the Polytechnic University of Catalonia (UPC) for the support that it has given us during these years. We would also like to thank the Centre for Development Cooperation (CCD) of the UPC for their assistance with other studies related to solar photovoltaic energy. I would also like to thank Jacqueline Cole for her support and dedication with the English translation.

\section{References}

[1] Miguel Alonso Abella. "Sistemas Fotovoltaicos: Introducción al diseño y dimensionado de instalaciones de energía solar fotovoltaica”. Era Solar, segunda edición, 2005.

[2] N. Okada, S. Yamanaka, H. Kawamura, and H. Ohno, "Energy loss of photovoltaic system caused by irradiance and incident angle," in Proc. 3rd IEEE Photovoltaic Energy Convers. World. Conf., 2003, pp. 2062- 2065.

[3] E. Caamaño, E. Lorenzo "On-site characterisation of gridconnected PV systems.” Era Solar, 14th EC Photovoltaic Solar Energy Conference, Barcelona, pp. 1536-1539, 1998.

[4] E. Lorenzo, "Retratos de la conexión fotovoltaica a la red IV: Seguidores y huertas solares", Era Solar, 119, 6-23, 2004.

[5] E. Lorenzo, "La energía que producen los sistemas fotovoltaicos conectados a la red: El mito del 1300 y el cascabel del gato", Era Solar, 107, 22-28 (2002).

[6] S. Ransome et al. 'Analysis of measured $\mathrm{kWh} / \mathrm{kWp}$ from grid tied system - Modeling different technologies worldwide with real data', 17th European photovoltaic Solar Energy Conference, Munich, pp. 431-435, 2002.

[7] Y. Ueda, K. Kurokawa, T. Itou, K. Kitamura, Y. Miyamoto, M. Yokota, and H. Sugihara, "Performance ratio and yield analysis of grid connected clustered PV systems in Japan,” in Proc. 4th IEEE Photovoltaic Energy Convers. World. Conf., pp. 2296-2299, 2006.

[8] T.-F.Wu, C.-H. Chang, Y.-D. Chang, and K.-Y. Lee, "Power loss analysis of grid-connection photovoltaic systems," in Proc. Power Electronics and Drive Systems (PEDS) Conf., 2009, pp. 326-331.

[9] M. Alonso-Abella, F. Chenlo, A model for energy production estimation of PV grid connected systems based on energetic losses and experimental data. On site diagnosis, 19th European Photovoltaic Solar Energy Congference, June, Paris, 2447-2450, 2004. 